\title{
Green streetscape and walking: Exploring active mobility patterns in dense and compact cities ${ }^{1}$
}

\author{
Guillem Vich ${ }^{\mathrm{a}}$, Oriol Marquet ${ }^{\mathrm{c}}$, CarmeMiralles-Guasch ${ }^{\mathrm{ab}}$
}

a

Geography Department, Autonomous University of Barcelona, Cerdanyola del Vallès, 08193 Barcelona, Spain

b

ICTA (Institute of Environmental Science and Technology), Cerdanyola del Vallès, 08193 Barcelona, Spain

Department of Parks, Recreation and Tourism Management - North Carolina State University (NCSU), 2800 Faucette Dr. Raleigh, NC 27695, USA

\section{Abstract}

Being physically active in natural environments has been linked with multiple mental and physical health benefits. However, not all urban contexts can provide their residents the same access to green areas for walking and sport activities. Mediterranean cities provide open spaces for physical activity that differ from those of Northern European cities. This study explores both conventional spaces in the form of public parks and urban green spaces, i.e. beaches, tree-lined streets, boulevards and public squares, in relation to the daily walking levels of residents in a Mediterranean city, such as Barcelona by presenting findings based on examining and assessing spatio-temporal exposure levels measured with the help of smartphones and publicly available $\underline{\text { GIS }}$ layers. To achieve this, both exposure and daily walking time were measured from GIS and GPS-based smartphone tracking data for 127 adult individuals from Barcelona, Spain. Based on these measurements, it was determined that the presence of large-scale open spaces for physical activity, such as beaches or large parks in the participants' daily walking routes, proved to have the highest association with daily walking time. Also, underexplored forms of nature, such as street trees were also positively

\footnotetext{
${ }^{1}$ Proofreading and editing suggestions of this manuscript have been done by the professional services of SCP Translations (scpaguirigan.wordpress.com).
} 
correlated with individual walking levels. Additionally, small-scale public spaces, such as public squares and boulevards, indicated a considerably negative association with walking time. The findings from this study confirm existing evidence on the health benefits of urban greenness and broaden the analytical focus on the role and impact of green space provision on physical health. Altogether, street trees and the presence of both blue and traditional green spaces proved to be significant factors of increased walking levels.

\section{Background}

Walking is considered to be one of the most common physical activities among the adult population due to its associated increments in individual energy expenditures (Brownson, Jones, Pratt, Blanton, \& Heath, 2000; Lachapelle \& Pinto, 2016). This becomes more relevant in view of the recent findings of the World Health Organization that identify physical inactivity as the fourth leading risk factor for global mortality, as it leads to coronary heart disease and chronic conditions including hypertension, noninsulin-dependent diabetes, colon cancer, osteoarthritis and osteoporosis (WHO, 2010). To address these health concerns, public health officials and academics have identified active travel, i.e. walking or cycling, as a pathway towards minimising sedentary lifestyles and an acceptable source of exercise for achieving optimal health standards (Carlson et al., 2015; Sallis, Frank, Saelens, \& Kraft, 2004).

Apart from the various elements of urban planning and design that have been conducive to walking (Cervero \& Kockelman, 1997; Sallis et al., 2015), a growing body of literature has linked people's access to nature with multiple mental and physical health benefits (Hartig, Mitchell, de Vries, \& Frumkin, 2014; Markevych et al., 2017; Tsai et al., 2018). In fact, available greenness in structured urban green spaces has proven to reduce stress (Sarkar, Webster, \& Gallacher, 2018; van Herzele \& de Vries, 2012), promote socialising with friends (De Vries, van Dillen, Groenewegen, \& Spreeuwenberg, 2013), and diminish the levels of air pollution, heat and noise (Baró et al., 2014; Basagaña et al., 2011; Pathak, Tripathi, \& Mishra, 2008). Moreover, these spaces have been linked with increased physical activity levels (Douglas, Lennon, \& Scott, 2017; Markevych et al., 2017), since they provide a safe, accessible and attractive 
setting for walking and physical activity practices (Almanza, Jerrett, Dunton, Seto, \& Ann Pentz, 2012; Schipperijn, Bentsen, Troelsen, Toftager, \& Stigsdotter, 2013).

Public parks and gardens are the most widely researched forms of green space (Koohsari et al., 2015). However, the presence of nature is not only evident in public parks and gardens. Street trees and their canopies are common natural elements found in most urban areas in Europe. Apart from being a source of nature, research has found that they also increase street walkability (Cervero \& Kockelman, 1997; Southworth, 2005; Talavera-Garcia \& Soria-Lara, 2015). Together with streets, boulevards, and avenues with trees, also public squares and pocket parks are underexplored forms of green space and facilitators of several health benefits (Abelt \& McLafferty, 2017), including increased physical activity. In Mediterranean cities, where the provision of public parks tends to be lower than in other urban areas (Akpinar, 2016; Fuller \& Gaston, 2009), public squares and pocket parks could compensate for the absence of natural parks as a source of nature (Taylor, Wheeler, White, Economou, \& Osborne, 2015). Urban residents can use these public spaces for resting, walking and socialising while enjoying access to urban greenness (Corraliza, 2000; Ward Thompson, 2002). Previous literature has linked the provision of street trees with several health benefits, such as improved general health perception (van Dillen, de Vries, Groenewegen, \& Spreeuwenberg, 2012), lower depression levels (Sarkar et al., 2018; Taylor et al., 2015) and positive birth outcomes (Abelt \& McLafferty, 2017). However, there are still few studies linking tree-lined streets as a mediator of physical health. In comparison to other green spaces, such as natural parks related to recreative walking, not only do green streets enable walking as a means of self-transportation along aesthetically pleasant routes (Sallis, Floyd, Rodriguez, \& Saelens, 2012), but they could also become optimal places for recreational walking (Hahm, Yoon, Jung, \& Kwon, 2017; Lu, Sarkar, \& Xiao, 2018). Some current studies provide evidences associating higher tree densities with increased walking levels among adults ( $\mathrm{Lu}$ et al., 2018; Sarkar et al., 2015), or improved active travel and preventing obesity among children (Larsen et al., 2009; Lovasi et al., 2013). Nevertheless, more research is needed. Furthermore, many Mediterranean urban areas feature another distinct open space that provides people to have contact with nature, socialise and be physically active: the beach. This space, often considered as type of green space (WHO, 2016), is also known as a coastal blue space and being exposed to it has been previously linked with similar health benefits as green 
spaces (Hipp \& Ogunseitan, 2011), particularly with increased physical activity levels (Galland \& Hansen, 2012; Gascon, Zijlema, Vert, White, \& Nieuwenhuijsen, 2017).

Another major topic in health-related green space studies is the objective measurement of urban greenness. Recently, the relationship between this environmental feature and health benefits has further examined and developed thanks to technologies, such as the Geographical Information Systems (GIS) (Rojas, Páez, Barbosa, \& Carrasco, 2016; Troped, Wilson, Matthews, Cromley, \& Melly, 2010). Conventional exposure measurements, such as residential proximity to green spaces, are now accurately documented by means of street network distances thanks to GIS, which not only informs on the static potential access to greenness, but omits the available greenery in open spaces beyond conventional natural parks (Koohsari et al., 2015). Other utilised vegetation indicators also obtained by using GIS tools, such as the Normalized Difference Vegetation Index (NDVI) and the street tree density of an urban area, are helpful in examining the provision of greenness in different sorts of open spaces (Marquet et al., 2019). On the one hand, the NDVI indicates the overall vegetation level in a particular territory via satellite images; however, it still does not differentiate between the various types of greenness found in parks, street trees or private gardens (Markevych et al., 2017) despite recent efforts to improve the features of this tool (Shoshany, 2012). On the other hand, the amount of street trees has become an increasingly used indicator of urban greenness, as it is a fine-grained measure for filtering the amounts and types of trees according to the area of analysis (Abelt \& McLafferty, 2017; Sarkar et al., 2015; Taylor et al., 2015).

New sources of information, such as Global Positioning Systems (GPS), have also provided individual data for detecting precise walking patterns and the consequent exposure to the surrounding environment. GPS data, especially when combined with GIS spatial analysis, has been widely used not only for detecting levels of physical activity in green spaces (Almanza et al., 2012; Andersen, Klinker, Toftager, Pawlowski, \& Schipperijn, 2015; James et al., 2017), but also measuring precise people-based exposure levels based on the mobility patterns of individuals in the surrounding environment, such as activity spaces(Hirsch, Winters, Ashe, Clarke, \& McKay, 2015; Holliday, Howard, Emch, Rodríguez, \& Evenson, 2017). GPS-based tracking measurements help minimise the challenges experienced with conventional place-based methods, such as the potential residential self-selection bias (Toftager et al., 2011), the 
Ecological Fallacy (Sarkar et al., 2015), and the so-called "Modifiable Area Unit Problem" or "local trap" (Vallée, Le Roux, Chaix, Kestens, \& Chauvin, 2014). These measurements predefine the scale of the environmental exposure at an administrative unit level (neighbourhood, census) or at buffered distances from residences, not including other visited locations by individuals (Kwan, 2012; Vich, Marquet, \& Miralles-Guasch, 2017). However, time-spatial measurements also include other challenges, such as the so-called "Selective Daily Mobility Bias", by which the resulting environmental exposures obtained from mobility patterns could be attributed to individual preferences, which lead to possible biased causal effects (Chaix et al., 2013).

Finally, the appearance of GPS-enabled smartphones and their widespread availability has widened the possibilities of collecting data for both urban and environmental exposure studies. Although data-loss situations may occur due to battery drainage (Birenboim \& Shoval, 2015), on-board accelerometers and GPS in smartphones can precisely monitor individual spatial and temporal behaviour while lowering the participation burden for users (i.e. carrying and charging a GPS device) (Hirsch et al., 2014). Compared to GPS loggers, smartphone tracking data provides access to larger population samples and geographic ranges during longer observation periods, while posing relevant questions to study subjects on the go (Marquet, Alberico, \& Hipp, 2018) as well as promoting PA practices and sustainable mobility habits (Bopp et al., 2016). Apart from the available literature on urban planning and transportation, smartphone tracking data has concretely helped in tracking travel behaviour patterns, improving self-reported information and preventing common mobility survey biases (Birenboim \& Shoval, 2015; Delclòs-Alió, Marquet, \& Miralles-Guasch, 2017; Patterson \& Fitzsimmons, 2016; Vich et al., 2017). From a health perspective, Hirsch et al. (2014) analysed the types of physical activities tracked by means of an app and the locations they occur in. More recently, Althoff et al. (2017) used smartphone tracking data to explore walking-derived physical activity patterns in 111 countries around the world, whereby they focused on the role of the built environment and people's incomes. Due to its novelty, only few studies have used smartphone tracking data to examine the relationship between exposure to green spaces (Vich, Marquet, \& Miralles-Guasch, 2018) and physical activity patterns (Donaire-Gonzalez et al., 2016; Hirsch et al., 2014) or the influence of trees on the selection of specific walking routes (Hahm et al., 2017). 
The aim of this study is to examine the association between different types of urban green spaces that have so far been overlooked or not sufficiently studied (parks and treelined streets, boulevards and public squares) and daily walking levels in a Mediterranean city, such as Barcelona. This research uses GPS-based smartphone tracking data to obtain exposure measurements from the mobility patterns of a group of individuals in order to analyse the relationship between green space exposure and daily walking time.

\section{Methods}

The city of Barcelona, which is the study area, had a population of 1.6 million in 2016 and an average population density of 15,740 inhabitants per $\mathrm{km}^{2}$ (BCN, 2016b). Its density, morphology and street design make this city a highly walkable urban area (Dura-Guimera, 2003; Marquet \& Miralles-Guasch, 2015). Compared to other urban areas, its lower number of public nature parks (Fuller \& Gaston, 2009) is partly compensated by high quality open spaces, such as streets, boulevards and public squares (Garcia-Ramon, Ortiz, \& Prats, 2004), which are well provided with street trees (Pauleit et al., 2002). These spaces represent lively settings for walking or strolling as well as for social gathering (Corraliza, 2000; Ward Thompson, 2002). This provision of diverse green spaces makes Barcelona an ideal site for examining the relationship between walking levels and exposure to different sources of urban greenery.

\subsection{Participants and data collection}

We used a subsample of voluntary respondents to the 2017's Autonomous University of Barcelona (UAB) Mobility Survey ( $\mathrm{n}=263$ ). This was complemented with a snowball process $(n=64)$, mailing lists $(n=11)$ and ads placed in social networks $(n=9)$. Altogether, we gathered a total of 347 participants. The recruiting campaign called for people interested in participating in an academic research on active mobility called “Campus Mobility 2017”. To assess their daily walking patterns, participants were asked to download and install the MOVES@ smartphone app, which is available for free on both Android and IOS). This GPS-based app provides users with a diary of personal mobility, in which they can record information on travelled distances, durations, steps, and burned calories. At the same time, the app recognise routes taken by the users, their 
visited location and transportation modes throughout the day (Evenson \& Furberg, 2017). Between April and June 2017, participants downloaded and kept MOVES@ activated for seven days, and at the end of the tracking exercise, they took part in an online survey, in which they answered several profile questions (gender, age, commuting transport mode and residence address). This app was recently applied in a similar study on green space exposure (Vich et al., 2018). The downloading, installation and use of MOVES@ $\odot$ by participants involved their explicit consent to the terms and conditions of the app developer, and the confidentiality of their data was ensured by implementing different user codes during data collection, data processing and data analysis stages. The study was approved by the Ethics Committee on Animal and Human Experimentation of the Autonomous University of Barcelona (code CEEAH$3657)$.

\subsection{Measurements}

At the end of the fieldwork, a total of 466,875 tracking points was registered using the MOVES@ API. GPS points are georeferenced and transport modes assigned by this app when movement is detected by the smartphone's accelerometer (Protogeo, 2016). The database required minimal cleansing, since trips and stops were detected by the app's algorithms. From the raw database, tracking points registered by residents in Barcelona $(\mathrm{N}=227,836)$ and registered within Barcelona's administrative limits $(\mathrm{N}=136,648)$ were selected. This app categorised georeferenced points either as a "waiting" or "moving" tracking point to differentiate whether these points were part of a trip or a stop. A "waiting" tracking point implied standing still, while one "moving" tracking point is defined by the app as comprising consecutive points, which exhibit a certain speed and acceleration and a transport mode that implies movement, i.e. walking, running, cycling or motorised transport, assigned by the smartphone's accelerometer (Protogeo, 2016). Of the 136,648 tracking points registered by residents within the city limits of Barcelona, 85,112 "moving" tracking points categorised as "walking" made the final sample after the data cleansing process and accounting for days of participation.

The final 85,112 GPS tracking points obtained from MOVES@ $\odot$ were utilised for measuring both the users' walking patterns and their environmental exposure to greenness. In order to examine the amount of physical activity generated by walking across the city, daily walking time was selected as the main outcome variable. This 
outcome was calculated by tallying the consecutive points assigned by MOVES $\odot$ as "walking" points within Barcelona's boundaries into different trip segments using the Tracking Analyst function of the ArcGIS 10.3 toolbox. Trip segments or trajectories registered at a higher speed than $6 \mathrm{~km} / \mathrm{h}$ and lasting over 3 minutes were excluded, and thus following commonly accepted data cleansing thresholds (Cho, Rodríguez, \& Evenson, 2011). A sample of the walking trajectories of three participants was extracted and visually checked to detect any incoherent transport mode assignments and erroneous multimodal trajectories. Of the total trajectories, 95\% were correctly assigned. Days with remarkably low walking levels according to their Z-score were discarded (daily walking time under $1 \mathrm{~min}$ per day), thereby leaving the final sample at 127 individuals that contributed to a total of 772 complete days of data (average of 6.1 days/person), which concurs with previous research (Costa et al., 2015; Robinson \& Oreskovic, 2013). The participant sample $(\mathrm{n}=127)$ was fairly balanced according to gender $($ male $=52$; female $=75)$ and predominantly young under 29 years $=87 ; 30-41$ years $=29 ; 42-64$ years $=11$ ).

The methodological workflow followed is schematised in Figure 1.

Figure 1. Methodological scheme.

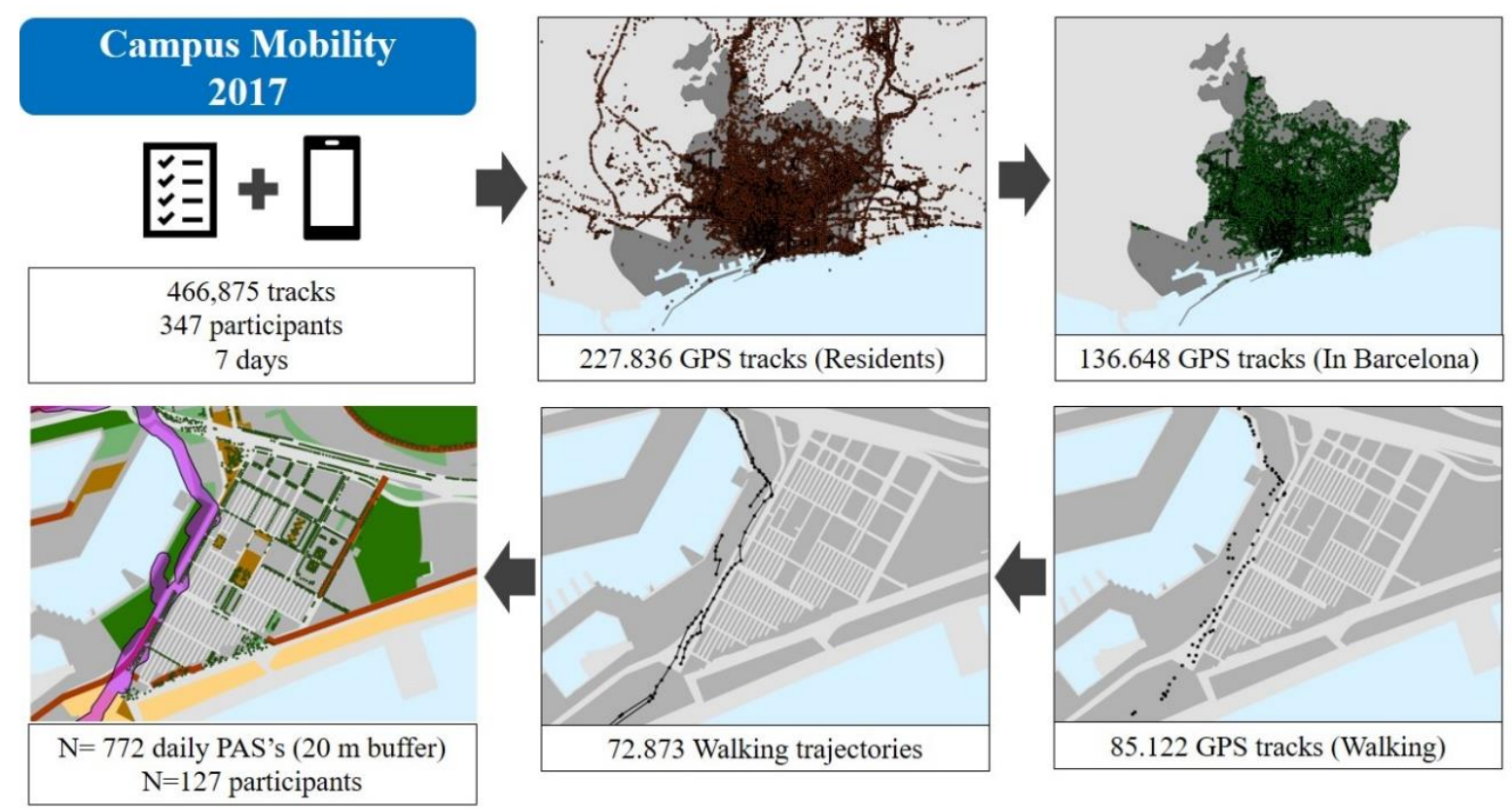

Source: Own production.

To capture the level of exposure to urban greenness, a GPS-based buffered trip segment called "Pedestrian Activity Space (PAS)" was calculated for each day of participation to measure the presence of greenness elements that individuals were exposed to. First, the 
calculation of all PAS's consisted of executing a 20-meter buffer around all the geocoded walking trip segments with ArcGIS 10.3@. 772 PAS's were generated, which corresponded to the 772 participated days from 127 individuals (See Fig. 2). Although the buffer size of 20 meters was smaller than similar studies (Burgoine, Jones, Namenek Brouwer, \& Benjamin Neelon, 2015; Hirsch et al., 2015), this size was the average street width of Barcelona; thus, the buffer size was adapted to the spatial scale of the study.

Figure 2. Example of a Pedestrian Activity Space (PAS).

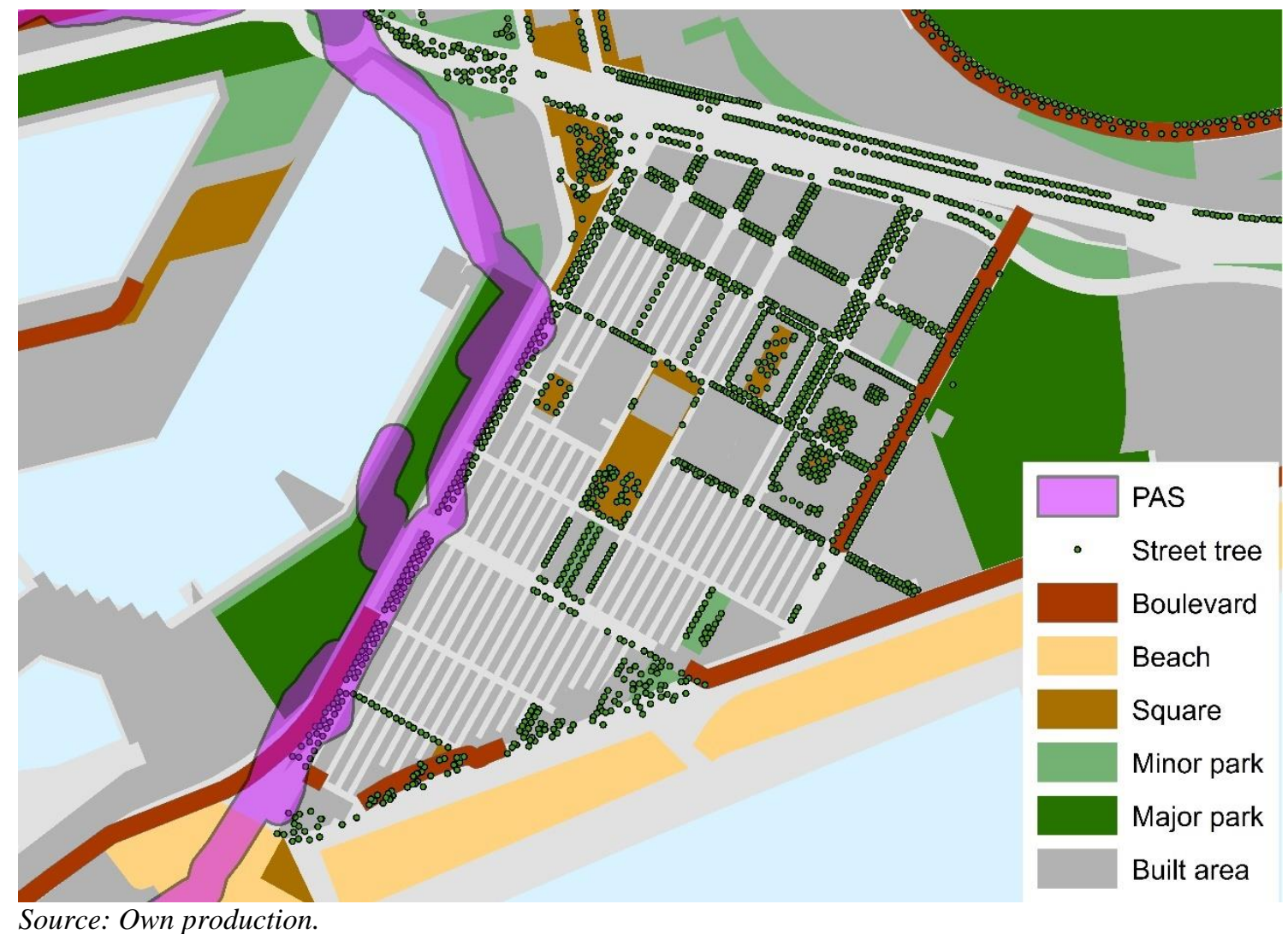

Publicly available spatial information on land uses in Barcelona, street intersections and geolocated trees planted in the city in shapefile formats were used to describe the surrounding green environment: public parks, street trees, boulevard, public squares and beaches (see also Fig. 1). The city's Land Use Map (BCN, 2016a) was utilised to identify "large parks". Only land use polygons categorised as urban parks $(\mathrm{N}=93)$, and forestry parks $(\mathrm{N}=1)$ by this map larger than 2 hectares were considered (Natural England, 2010), whereas green areas under this threshold were identified as small parks $(\mathrm{N}=1,760)$ with sizes ranging between 20,020 and $1,640,000 \mathrm{~m}^{2}$ and 16.88 and 19,340 
$\mathrm{m}^{2}$, respectively. Beaches $(\mathrm{N}=1)$, public squares $(\mathrm{N}=359)$ and boulevards $(\mathrm{N}=91)$ were identified by combining the land use map with the street category from the street network shapefile (BCC, 2014). No pre-processing was required to identify street trees $(\mathrm{N}=153,414)$ included in the Street Tree Map in shape file (BCN, 2014). This only included those trees placed outside park borders.

We then used the Spatial Join tool of ArcGIS 10.3@ to determine the presence of urban green elements included within each PAS. We calculated the proportion of these elements per PAS buffer, by dividing it by their total area $\left(\mathrm{km}^{2}\right.$ of green element/total $\mathrm{km}^{2}$ of PAS). Proportions of these elements were applied for measuring and comparing concentrations of elements in PAS's with different areas to control for any size difference. For street trees, tree density (trees/total $\mathrm{km}^{2}$ of PAS) was utilised to calculate the proportion of this element per PAS buffer. Street intersection density was also included in the analysis as a proxy of the different morphologies available in the city that can also influence walking patterns. (Christiansen et al., 2016) Day type of participation (week and weekend) was analysed to detect differences between utilitarian and recreational walking. Furthermore, the individual exposure to these environmental features was controlled by several profile and mobility variables, such as gender, age and commuting mode, which includes active (walking and cycling), public (train or bus) and private transport means (car or motorcycle), according to the data extracted from the profile questionnaire.

\subsection{Statistical Analysis}

Median differences were used to analyse variations in the amount of walking minutes between the categories of the selected independent variables (gender, age, commuter type, day type, intersection density, tree density, proportion of boulevards, proportion of public squares, proportion of small parks, proportion of large parks, proportion of beaches) and their significance levels were calculated using the Mann-Whitney U-test and the Kruskal-Wallis test due to the skewness of the sample of daily walking time. The descriptive statistics are followed by a mixed-effects multilevel regression analysis to test the association between the set of explanatory variables and the log-transformed outcome variable in which the 772 PAS's were set as level 1, at which explanatory factors were measured among 127 participants with individual-level data as level 2 . The fixed effect analysis aimed at measuring differences in walking time between 
individuals after controlling for the independent variables. The random effect explored the variation of daily walking time corresponding to the different daily exposure measures and profile factors at the PAS level. No multicollinearity was detected between the explanatory variables exhibiting variance inflation factor (VIF) values ranging between 1.03 and 1.17 .

\section{Results}

\subsection{Descriptive statistics}

Table 1 shows descriptive statistics for walking time across the different type of explanatory factors. Among the analysed variables, neither gender nor age proved to be significant explanatory factors of daily walking in the bivariate analysis. Male and female participants registered similar amounts of walking minutes, whereas individuals between 30 and 41 years old registered higher median values than people in their 20 s or those over 42 years old. The day type also did not show any significant influence on walking time, although higher median values were registered during weekends than weekdays.

Variables, which describe the exposure to the surrounding environment (parks, beaches, squares, boulevards, trees and intersections) on participants' daily walks and the utilised commuting mode, showed significant results (also Table 1). The PAS's, which were registered by active commuters and public transport users, generated higher walking time than private transport commuters. In the same way, those individuals that incorporate large open spaces in their PAS, such as large parks and beaches, registered twice and four times as much daily walking minutes at the end of the day, respectively, than those who did not. Regarding smaller open spaces, those PAS's not indicating any presence of small parks, public squares and boulevards generated the lowest walking time per day. However, those with a low proportion of these elements generated higher walking time than those with intermediate and higher proportions. Regarding street trees, those individuals, who walked in higher tree density areas, registered more walking time than those who walked in the lower density areas. However, the highest median walking times were registered by participants exposed to intermediate tree densities, i.e. medium-low and medium-high, along their daily walks. The same pattern was detected when analysing the connectivity of the street pattern with the intersection density. PAS's with a higher density of intersections registered higher walking times 
than those with lower densities; the highest daily walking times were concentrated in areas of intermediate intersection density.

Table 1. Median daily walking time using explanatory factors at two levels.

\begin{tabular}{|c|c|c|c|c|c|}
\hline \multirow{2}{*}{ Explanatory factors } & Categories & $\mathbf{N}$ & Minutes $^{a}$ & IQR & $p$ \\
\hline & Total & 772 & 25.13 & 37.58 & \\
\hline \multirow{2}{*}{ Gender } & Male & 331 & 25.03 & 42.47 & \multirow{2}{*}{0.623} \\
\hline & Female & 441 & 25.23 & 34.72 & \\
\hline \multirow{3}{*}{ Age } & $<=29$ y.o. & 521 & 23.72 & 34.83 & \multirow{3}{*}{0.080} \\
\hline & $30-41$ y.o. & 182 & 28.84 & 42.27 & \\
\hline & $>=42$ y.o. & 69 & 24.83 & 32.80 & \\
\hline \multirow{3}{*}{ Employment status } & \begin{tabular}{|l} 
Student \\
\end{tabular} & 411 & 23,70 & 34.68 & \multirow{3}{*}{0.641} \\
\hline & Employed & 356 & 26.54 & 41.90 & \\
\hline & Unemployed & 4 & 17.68 & 84.88 & \\
\hline \multirow{3}{*}{ Coтmuter type } & Active transport & 112 & 29.01 & 39.60 & \multirow{3}{*}{$0.001 *$} \\
\hline & Public transport & 556 & 26.58 & 38.66 & \\
\hline & Private transport & 92 & 13.06 & 21.30 & \\
\hline \multirow{2}{*}{ Day type } & Week & 571 & 25.23 & 37.10 & \multirow{2}{*}{0.755} \\
\hline & Weekend & 194 & 24.25 & 38.54 & \\
\hline \multirow{4}{*}{$\begin{array}{l}\text { Intersection density }{ }^{b} \\
\left(\text { counts } / \mathrm{km}^{2}\right)\end{array}$} & Low & 107 & 8.73 & 13.43 & \multirow{4}{*}{$0.001^{*}$} \\
\hline & Medium-Low & 334 & 30.98 & 39.06 & \\
\hline & Medium-High & 230 & 33.73 & 39.35 & \\
\hline & High & 101 & 19.02 & 36.33 & \\
\hline \multirow{4}{*}{$\begin{array}{l}\text { Tree density }{ }^{c} \\
{\left.\text { (counts } / \mathrm{km}^{2}\right)}\end{array}$} & Low & 70 & 6.00 & 7.94 & \multirow{4}{*}{$0.001^{*}$} \\
\hline & Medium-Low & 457 & 24.72 & 34.53 & \\
\hline & Medium-High & 179 & 35.08 & 37.32 & \\
\hline & High & 66 & 38.93 & 37.90 & \\
\hline \multirow{4}{*}{ Boulevard proportion ${ }^{d}$} & No contact & 450 & 11.18 & 14.84 & \multirow{4}{*}{$0.001^{*}$} \\
\hline & Low & 793 & 40.80 & 38.97 & \\
\hline & Medium & 371 & 28.15 & 28.10 & \\
\hline & High & 100 & 9.61 & 11.78 & \\
\hline \multirow{4}{*}{ Public square proportion ${ }^{e}$} & No contact & 726 & 16.28 & 22.78 & \multirow{4}{*}{$0.001 *$} \\
\hline & Low & 820 & 39.26 & 36.47 & \\
\hline & Medium & 126 & 28.82 & 35.76 & \\
\hline & High & 42 & 14.31 & 32.53 & \\
\hline \multirow{4}{*}{ Small park proportion ${ }^{f}$} & No contact & 546 & 12.27 & 16.79 & \multirow{4}{*}{$0.001^{*}$} \\
\hline & Low & 677 & 39.62 & 36.08 & \\
\hline & Medium & 310 & 35.94 & 33.81 & \\
\hline & High & 181 & 25.80 & 28.66 & \\
\hline \multirow{4}{*}{ Large park proportion ${ }^{g}$} & No contact & 1,384 & 23.58 & 29.95 & \multirow{4}{*}{$0.001 *$} \\
\hline & Low & 93 & 45.12 & 44.85 & \\
\hline & Medium & 117 & 53.43 & 41.82 & \\
\hline & High & 120 & 33.09 & 36.65 & \\
\hline \multirow{3}{*}{ Beach proportion ${ }^{h}$} & No contact & 1,675 & 26.32 & 32.73 & \multirow{3}{*}{$0.001 *$} \\
\hline & Medium & 10 & 99.13 & 62.44 & \\
\hline & High & 28 & 61.88 & 59.66 & \\
\hline
\end{tabular}

*Significant p-value obtained from Kruskal-Wallis non-parametric one-way Analysis of Variance (ANOVA) or Wilcoxon Rank Sum test across individual and environmental factors.

${ }^{a}$ Median walking minutes per day.

${ }^{b}$ Categories obtained using 1 standard deviation: Low ( $\left.<=2004.73\right) ;$ Medium-Low (2004.74 - 3417.74); Medium$\operatorname{High}(3417.75$ - 4830.75); High (>4830.76).

${ }^{c}$ Categories obtained using 1 standard deviation: Low ( $\left.<=96.37\right) ;$ Medium-Low (96.38 - 228.33); Medium-High (228.34 - 360.29); High (>360.30).

${ }^{d}$ Categories obtained using 1 standard deviation: No contact $(<=0.00)$; Low (0.01-0.30); Medium (0.31-1.04); High (>1.05).

${ }^{e}$ Categories obtained using 1 standard deviation: No contact $(<=0.00) ;$ Low (0.01-0.02); Medium (0.02 -0.03); High (>0.04). 
${ }^{f}$ Categories obtained using 1 standard deviation: No contact $(<=0.00) ;$ Low (0.01-0.29); Medium (0.30 - 0.81); $\operatorname{High}(>0.82)$.

${ }^{g}$ Categories obtained using 1 standard deviation: No contact $(<=0.00) ;$ Low $(0.01-0.10) ;$ Medium $(0.11-0.47)$; High (>0.48).

${ }^{h}$ Categories obtained using 1 standard deviation: No contact (0.00-0.02); Medium (0.03-0.10); High (>0.11). The Low exposure category was excluded since there was only one case.

Table 2 shows the multilevel regression analysis between walking time and the different explanatory factors at two levels: individual (level 2) and PAS (level 1). The intraclass correlation of daily walking time showed that $38 \%$ of the variation in registered walking minutes was attributable to differences between the participants. Environmental exposures measured along walking routes were all significantly associated with walking time at the individual level. The environmental factors with the highest association were beach proportion $(\mathrm{B}=2.298)$ and large park proportion $(\mathrm{B}=0.153)$, whereas tree density $(B=0.001)$ also ended up being significant. Albeit showing negative association with the outcome variable, other significant environmental factors were, public square proportion $(\mathrm{B}=-1.420)$ and boulevard proportion $(\mathrm{B}=-0.108)$. The only non-significant exposure factor was small park proportion, which also showed a negative relationship with walking time. Furthermore, being a private transport commuter was also negatively associated with walking time and no significant influence was found for day type (reference weekend days), gender (reference female), employment status (reference student) and age. After controlling for the explanatory factors at the individual level, $34.16 \%$ of the variation in walking levels was still attributable to differences between participants. Of these differences, $29.32 \%$ corresponds to the different daily exposures to greenness at the PAS level. Therefore, the individual participants' different daily exposure to greenness can explain $10.01 \%$ (29.32\% of $34.16 \%)$ of the total variance of walking time. Both variations among participants within their PAS were found to be significant. 
Table 2. Mixed-effects linear regression coefficient for daily walking time (minutes) of exposure measures ${ }^{a b}$.

\begin{tabular}{|c|c|c|c|c|c|c|}
\hline \multicolumn{7}{|c|}{ Explanatory factors of daily walking time } \\
\hline Fixed effects & $\boldsymbol{B}$ & St. err. & $t$ & $p$ & \multicolumn{2}{|c|}{ CI $(95 \%)$} \\
\hline Intersect & 1.437 & 0.261 & 5.506 & $0.001 *$ & 0.919 & 1.954 \\
\hline Dummy male & 0.047 & 0.056 & 0.846 & 0.399 & -0.064 & 0.159 \\
\hline Age & 0.007 & 0.003 & 1.950 & 0.054 & 0.000 & 0.013 \\
\hline Dummy student & 0.009 & 0.032 & 0.271 & 0.787 & -0.055 & 0.073 \\
\hline Dummy private transport & -0.296 & 0.087 & -3.415 & $0.001 *$ & -0.468 & -0.124 \\
\hline Environmental factors & & & & & & \\
\hline Intersection density & $0.008^{c}$ & 0.000 & 1.933 & 0.054 & 0.000 & 0.000 \\
\hline Tree density & $0.001^{\mathrm{c}}$ & 0.000 & 5.895 & $0.001 *$ & 0.000 & 0.000 \\
\hline Boulevard proportion & -0.108 & 0.016 & -6.864 & $0.001^{*}$ & -0.139 & -0.077 \\
\hline Public square proportion & -1.420 & 0.430 & -3.305 & $0.001 *$ & -2.265 & -0.576 \\
\hline Small park proportion & -0.033 & 0.036 & -0.918 & 0.359 & -0.105 & 0.038 \\
\hline Large park proportion & 0.153 & 0.059 & 2.600 & $0.010 *$ & 0.037 & 0.268 \\
\hline Beach proportion & 2.298 & 0.581 & 3.953 & $0.001 *$ & 1.156 & 3.440 \\
\hline Day characteristics & & & & & & \\
\hline Day type & 0.034 & 0.032 & 1.069 & 0.286 & -0.028 & 0.096 \\
\hline Random effects & $B$ & St. err. & Wald Z & $p$ & \multicolumn{2}{|c|}{ CI $(95 \%)$} \\
\hline Residual & 0.111 & 0.007 & 16.071 & $0.001 *$ & 0.098 & 0.126 \\
\hline Participants & 0.058 & 0.011 & 5.047 & $0.001 *$ & 0.039 & 0.085 \\
\hline
\end{tabular}

B: Coefficient estimate; St. err.: Standard error; $t$ : $t$-value; $p$ : p-value; CI: Confidence interval; Wald Z: Wald test. *Significant p-value.

${ }^{a}$ This model is based on the log-transformed dependant variable: MVPA.

${ }^{b}$ Intraclass coefficient (ICC): 0.387 (null model), 0.342(full model). Proportion of the variance at Level 1(0.293)

${ }^{c}$ Change in outcome per unit change in IQR.

\section{Discussion}

The results showed a significant association of explanatory factors at both individual and Pedestrian Activity Space (PAS) levels in relation to walking time in Barcelona. Outcome variations at both interindividual (34.16\%) and PAS (10.01\%) levels indicated different walking levels among the 127 sampled participants.

The exposure to different green spaces and elements analysed in this paper has proven to be significantly associated with registered walking time at the end of the day. Of all the analysed factors, the strongest environmental factors were the presence of large open spaces, such as beaches and large parks, in the participants' PAS's, whereby being in contact with both blue and green large open spaces resulted in the highest association with daily walking time. These findings conform with conventional green space exposure academic studies, with which the presence of green areas and residential 
proximity thereto are related to increased walking levels (Kaczynski, Potwarka, Smale, \& Havitz, 2009; Lachowycz \& Jones, 2011; Sugiyama et al., 2013).

Regarding less explored forms of green spaces, this study also significantly contributes to the growing number of studies examining the relationship of street trees and positive physical activity outcomes (Larsen et al., 2009; Lovasi et al., 2013; Sarkar et al., 2015) by showing a positive association between exposure to tree density and the daily walking time of individuals. However, for public squares and boulevards, a significant negative association with walking levels was detected. These differentiated associations for small-scale open spaces could be due to their design and preferential uses, which make them more attractive for rather sedentary forms of recreation (Carmona, 2010; Gehl, 2010; Madanipour, 1999). Regarding profile-related factors, only those concerning mobility habits had an effect on daily walking time. Travelling to daily destinations by car has been long associated with a more sedentary lifestyle (Brownson, Boehmer, \& Luke, 2005), while using public transport has also been found to help meet physical activity recommendations (Lachapelle \& Pinto, 2016). In this study, those who used public transport for commuting, walked significantly more than those using private modes. Furthermore, no association was detected when examining how gender, age, employment status and day type affects daily walking time. The current literature highlights how women and young people are linked to healthier mobility patterns and increased walking times than men and older adults (Bauman et al., 2012; Rissel, Curac, Greenaway, \& Bauman, 2012). Although findings in this study did show differences in age and gender, these did not reach statistical significance. The fact that the sample mostly comprised of young participants might have had an influence in the results.

The present research, which is one of the few studies examining the relationship between the built environment and daily walking levels using individual exposure measures based on smartphone tracking data, provides promising results for future health and planning studies. The detected differentiated walking time patterns within a highly dense urban area, such as the city of Barcelona, conform with state-of-the-art studies on physical activity and environmental exposure research (Althoff et al., 2017; Donaire-Gonzalez et al., 2016; Hirsch et al., 2014). Moreover, the use of activity spaces for measuring the environmental exposure has proven to be a precise measurement, as only green spaces encountered along walking routes were registered. At the same time, this study addresses the need for examining environmental influences on human 
behaviour beyond residential areas while it aims to find true geographical contexts (Kwan, 2012; Matthews \& Yang, 2013; Vallée et al., 2014).

The utilisation of smartphone technology for examining spatial behaviour provides methodological improvements due to their widespread daily use, which reduces possible utilisation bias, as they make users less aware of their mobility patterns. The tracking data derived from smartphones proves to be an accessible data source for both health and planning studies due to their easy collection and the ease of use by study subjects.

However, this study is not without limitations. The issue of Selective Daily Mobility Bias (Chaix et al., 2013), which is common among most tracking-based exposure research, continues to be a challenge. Individuals might choose certain destinations and routes according to intrapersonal preferences when travelling or during leisure time rather than for the mere purpose of gaining exposure to the environment. For instance, this is clear in the case of exposure to large parks and beaches. Moreover, a straight causality between exposure measures and walking time should not be drawn, since exposure to green spaces does not necessarily imply that these are being used (Koohsari et al., 2015; Markevych et al., 2017). At any rate, this study does provide valuable findings concerning the often unexamined urban spaces and green elements, where participants can have physical activity (James et al., 2017), in this case, through daily walking.

The present findings further supplement existing evidence on the health benefits of green spaces by casting a new light and perspective on a wider approach regarding greenness provision. Based on the results of the study, public health and planning policies working towards creating and developing healthy and vital environments could consider greening the streetscape of streets or public squares as a complementary solution to park planning. Indeed, the evidences in this study reaffirm the unexplored potential of providing street greenery in urban greening strategies and policies. Together with other design elements, such as benches or wide sidewalks, providing streets with different forms of greenness, has the potential of enhancing the urban dimensions and functions of simple paths and roads. Streets could become both walkable spaces and areas for social gathering and activities. In this particular context, greening strategies, such as the planning of urban green networks or green corridors, gain higher relevance, since providing these systems improves both the walkability of urban systems as well as the accessibility to specifically allocated green spaces, such as nature parks. This 
potential is particularly relevant not only for dense and compact urban areas, such as Barcelona, which does not have sufficient space to provide large monofunctional green areas, but also for less dense urban areas aiming to improve the walkability and vitality of their streets and neighbourhoods.

\section{References}

Abelt, K., \& McLafferty, S. (2017). Green streets: Urban green and birth outcomes. International Journal of Environmental Research and Public Health, 14(7). http://doi.org/10.3390/ijerph14070771

Akpinar, A. (2016). How is quality of urban green spaces associated with physical activity and health? Urban Forestry and Urban Greening, 16, 76-83. http://doi.org/10.1016/j.ufug.2016.01.011

Almanza, E., Jerrett, M., Dunton, G., Seto, E., \& Ann Pentz, M. (2012). A study of community design, greenness, and physical activity in children using satellite, GPS and accelerometer data. Health and Place, 18(1), 46-54. http://doi.org/10.1016/j.healthplace.2011.09.003

Althoff, T., Sosič, R., Hicks, J. L., King, A. C., Delp, S. L., \& Leskovec, J. (2017). Large-scale physical activity data reveal worldwide activity inequality. Nature. http://doi.org/10.1038/nature23018

Andersen, H. B., Klinker, C. D., Toftager, M., Pawlowski, C. S., \& Schipperijn, J. (2015). Objectively measured differences in physical activity in five types of schoolyard area. Landscape and Urban Planning, 134, 83-92. http://doi.org/10.1016/j.landurbplan.2014.10.005

Baró, F., Chaparro, L., Gómez-Baggethun, E., Langemeyer, J., Nowak, D. J., \& Terradas, J. (2014). Contribution of ecosystem services to air quality and climate change mitigation policies: The case of urban forests in Barcelona, Spain. Ambio, 43(4), 466-479. http://doi.org/10.1007/s13280-014-0507-x

Basagaña, X., Sartini, C., Barrera-Gómez, J., Dadvand, P., Cunillera, J., Ostro, B., ... Medina-Ramón, M. (2011). Heat Waves and Cause-specific Mortality at all Ages. Epidemiology, 22(6), 765-772. http://doi.org/10.1097/EDE.0b013e31823031c5

Bauman, A. E., Reis, R. S., Sallis, J. F., Wells, J. C., Loos, R. J. F., \& Martin, B. W. 
(2012). Correlates of physical activity: Why are some people physically active and others not? The Lancet, 380(9838), 258-271. http://doi.org/10.1016/S01406736(12)60735-1

BCC. (2014). Street Network of Barcelona. Retrieved March 15, 2017, from http://w20.bcn.cat/cartobcn/

BCN. (2014). Street Trees of Barcelona. Retrieved March 1, 2017, from http://opendata-ajuntament.barcelona.cat/data/en/dataset/arbrat-viari

BCN. (2016a). Land Use Map from Barcelona City Council. Retrieved March 1, 2017, from http://w20.bcn.cat/cartobcn/

BCN. (2016b). Statistical Yearbook of Barcelona City. Barcelona.

Birenboim, A., \& Shoval, N. (2015). Mobility research in the age of the smartphone. Annals of the Association of American Geographers, 106(2), 283-291. http://doi.org/10.1080/00045608.2015.1100058

Bopp, M., Sims, D., Matthews, S. A., Rovniak, L. S., Poole, E., \& Colgan, J. (2016). There' s an app for that: development of a smartphone app to promote active travel to a college campus. Journal of Transport and Health, 3(3), 305-314. http://doi.org/10.1016/j.jth.2016.02.007

Brownson, R. C., Boehmer, T. K., \& Luke, D. A. (2005). DECLINING RATES OF PHYSICAL ACTIVITY IN THE UNITED STATES: What Are the Contributors? Annual Review of Public Health, 26, 421-443. http://doi.org/http://dx.doi.org/10.1146/annurev.publhealth.26.021304.144437

Brownson, R. C., Jones, D. A., Pratt, M., Blanton, C., \& Heath, G. W. (2000). Measuring physical activity with the behavioral risk factor surveillance system. Medicine and Science in Sports and Exercise, 32(11), 1913-1918.

Burgoine, T., Jones, A. P., Namenek Brouwer, R. J., \& Benjamin Neelon, S. E. (2015). Associations between BMI and home, school and route environmental exposures estimated using GPS and GIS: do we see evidence of selective daily mobility bias in children? International Journal of Health Geographics, 14(1), 8. http://doi.org/10.1186/1476-072X-14-8

Carlson, J. A., Saelens, B. E., Kerr, J., Schipperijn, J., Conway, T. L., Frank, L. D., ... Sallis, J. F. (2015). Association between neighborhood walkability and GPS- 
measured walking, bicycling and vehicle time in adolescents. Health and Place, 32, 1-7. http://doi.org/10.1016/j.healthplace.2014.12.008

Carmona, M. (2010). Contemporary Public Space, Part Two: Classification. Journal of Urban Design, 15(2), 157-173. http://doi.org/10.1080/13574801003638111

Cervero, R., \& Kockelman, K. (1997). Travel demand and the 3Ds: Density, diversity, and design. Transportation Research Part D: Transport and Environment, 2(3), 199-219. http://doi.org/10.1016/S1361-9209(97)00009-6

Chaix, B., Méline, J., Duncan, S., Merrien, C., Karusisi, N., Perchoux, C., ... Kestens, Y. (2013). GPS tracking in neighborhood and health studies: A step forward for environmental exposure assessment, A step backward for causal inference? Health and Place, 21, 46-51. http://doi.org/10.1016/j.healthplace.2013.01.003

Cho, G. H., Rodríguez, D. a., \& Evenson, K. R. (2011). Identifying walking trips using GPS data. Medicine and Science in Sports and Exercise, 43(2), 365-372. http://doi.org/10.1249/MSS.0b013e3181ebec3c

Christiansen, L. B., Cerin, E., Badland, H., Kerr, J., Davey, R., Troelsen, J., ... Sallis, J. F. (2016). International comparisons of the associations between objective measures of the built environment and transport-related walking and cycling: IPEN adult study. Journal of Transport and Health, 3, 467-478.

http://doi.org/10.1016/j.jth.2016.02.010

Corraliza, J. A. (2000). Landscape and Social Identity: the Construction of Territorial Identity. In Metropolis 2000 - Which Perspectives? Cities, Social Life and Sustainable Development: IAPS 16 Conference Proceedings on CD-Rom. Paris, France.

Costa, S., Ogilvie, D., Dalton, A., Westgate, K., Brage, S., \& Panter, J. (2015). Quantifying the physical activity energy expenditure of commuters using a combination of global positioning system and combined heart rate and movement sensors. Preventive Medicine, 81, 339-344. http://doi.org/10.1016/j.ypmed.2015.09.022

De Vries, S., van Dillen, S. M. E., Groenewegen, P. P., \& Spreeuwenberg, P. (2013). Streetscape greenery and health: Stress, social cohesion and physical activity as mediators. Social Science and Medicine, 94, 26-33. 
http://doi.org/10.1016/j.socscimed.2013.06.030

Delclòs-Alió, X., Marquet, O., \& Miralles-Guasch, C. (2017). Keeping track of time: A Smartphone-based analysis of travel time perception in a suburban environment. Travel Behaviour and Society, 9, 1-9. http://doi.org/10.1016/j.tbs.2017.07.001

Donaire-Gonzalez, D., Valentín, A., de Nazelle, A., Ambros, A., Carrasco-Turigas, G., Seto, E., ... Nieuwenhuijsen, M. J. (2016). Benefits of Mobile Phone Technology for Personal Environmental Monitoring. JMIR MHealth and UHealth, 4(4), e126. http://doi.org/10.2196/mhealth.5771

Douglas, O., Lennon, M., \& Scott, M. (2017). Green space benefits for health and wellbeing: A life-course approach for urban planning, design and management. Cities, 66, 53-62. http://doi.org/10.1016/j.cities.2017.03.011

Dura-Guimera, A. (2003). Population deconcentration and social restructuring in Barcelona, a European Mediterranean city. Cities, 20(6), 387-394.

http://doi.org/10.1016/j.cities.2003.08.004

Evenson, K. R., \& Furberg, R. D. (2017). Moves app: A digital diary to track physical activity and location. British Journal of Sports Medicine, 51(15), 1169-1170. http://doi.org/10.1136/bjsports-2016-096103

Fuller, R. A., \& Gaston, K. J. (2009). The scaling of green space coverage in European cities. Biology Letters, 5(3), 352-355. http://doi.org/10.1098/rsbl.2009.0010

Galland, D., \& Hansen, C. J. (2012). The roles of planning in waterfront redevelopment: From plan-led and market-driven styles to hybrid planning? Planning Practice and Research, 27(2), 203-225. http://doi.org/10.1080/02697459.2012.661669

Garcia-Ramon, M. D., Ortiz, A., \& Prats, M. (2004). Urban planning, gender and the use of public space in a peripherial neighbourhood of Barcelona. Cities, 21(3), 215-223. http://doi.org/10.1016/j.cities.2004.03.006

Gascon, M., Zijlema, W., Vert, C., White, M. P., \& Nieuwenhuijsen, M. J. (2017). Outdoor blue spaces, human health and well-being: A systematic review of quantitative studies. International Journal of Hygiene and Environmental Health, (April), 0-1. http://doi.org/10.1016/j.ijheh.2017.08.004

Gehl, J. (2010). Cities for people. Washington D.C.: Island Press. 
Hahm, Y., Yoon, H., Jung, D., \& Kwon, H. (2017). Do built environments affect pedestrians' choices of walking routes in retail districts? A study with GPS experiments in Hongdae retail district in Seoul, South Korea. Habitat International, 70(October), 50-60. http://doi.org/10.1016/j.habitatint.2017.10.002

Hartig, T., Mitchell, R., de Vries, S., \& Frumkin, H. (2014). Nature and Health. Annual Review of Public Health, 35(1), 207-228. http://doi.org/10.1146/annurevpublhealth-032013-182443

Hipp, J. A., \& Ogunseitan, O. A. (2011). Effect of environmental conditions on perceived psychological restorativeness of coastal parks. Journal of Environmental Psychology, 31(4), 421-429. http://doi.org/10.1016/j.jenvp.2011.08.008

Hirsch, J., James, P., Robinson, J. R. M., Eastman, K. M., Conley, K. D., Evenson, K. R., \& Laden, F. (2014). Using MapMyFitness to Place Physical Activity into Neighborhood Context. Frontiers in Public Health, 2(March), 1-9. http://doi.org/10.3389/fpubh.2014.00019

Hirsch, J., Winters, M., Ashe, M. C., Clarke, P. J., \& McKay, H. A. (2015). Destinations That Older Adults Experience Within Their GPS Activity Spaces: Relation to Objectively Measured Physical Activity. Environment and Behavior, 1-23. http://doi.org/10.1177/0013916515607312

Holliday, K. M., Howard, A. G., Emch, M., Rodríguez, D. A., \& Evenson, K. R. (2017). Are buffers around home representative of physical activity spaces among adults? Health and Place, 45(September 2016), 181-188. http://doi.org/10.1016/j.healthplace.2017.03.013

James, P., Hart, J. E., Hipp, J. A., Mitchell, J. A., Kerr, J., Hurvitz, P. M., ... Laden, F. (2017). GPS-based exposure to greenness and walkability and accelerometry-based physical activity. Cancer Epidemiology Biomarkers and Prevention, 26(4), 525532. http://doi.org/10.1158/1055-9965.EPI-16-0925

Kaczynski, A. T., Potwarka, L. R., Smale, B. J. A., \& Havitz, M. F. (2009). Association of Parkland proximity with neighborhood and park-based physical activity: Variations by gender and age. Leisure Sciences, 31(2), 174-191. http://doi.org/10.1080/01490400802686045

Koohsari, M. J., Mavoa, S., Villianueva, K., Sugiyama, T., Badland, H., Kaczynski, A. 
T., ... Giles-Corti, B. (2015). Public open space, physical activity, urban design and public health: Concepts, methods and research agenda. Health and Place, 33, 75-82. http://doi.org/10.1016/j.healthplace.2015.02.009

Kwan, M. P. (2012). The Uncertain Geographic Context Problem. Annals of the Association of American Geographers, 102(May 2015), 958-968.

http://doi.org/10.1080/00045608.2012.687349

Lachapelle, U., \& Pinto, D. G. (2016). Longer or more frequent walks: Examining the relationship between transit use and active transportation in Canada. Journal of Transport and Health, 3(2), 173-180. http://doi.org/10.1016/j.jth.2016.02.005

Lachowycz, K., \& Jones, A. P. (2011). Greenspace and obesity: A systematic review of the evidence. Obesity Reviews, 12(501), 183-189. http://doi.org/10.1111/j.1467789X.2010.00827.x

Larsen, K., Gilliland, J., Hess, P., Tucker, P., Irwin, J., \& He, M. (2009). The influence of the physical environment and sociodemographic characteristics on children's mode of travel to and from school. American Journal of Public Health, 99(3), 520526. http://doi.org/10.2105/AJPH.2008.135319

Lovasi, G. S., Schwartz-Soicher, O., Quinn, J. W., Berger, D. K., Neckerman, K. M., Jaslow, R., ... Rundle, A. (2013). Neighborhood safety and green space as predictors of obesity among preschool children from low-income families in New York City. Preventive Medicine, 57(3), 189-193. http://doi.org/10.1016/j.ypmed.2013.05.012

Lu, Y., Sarkar, C., \& Xiao, Y. (2018). The effect of street-level greenery on walking behavior: Evidence from Hong Kong. Social Science and Medicine, 208(December 2017), 41-49. http://doi.org/10.1016/j.socscimed.2018.05.022

Madanipour, A. (1999). Why are the design and development of public spaces significant for cities? Environment and Planning B: Planning and Design, 26(6), 879-891. http://doi.org/10.1068/b260879

Markevych, I., Schoierer, J., Hartig, T., Chudnovsky, A., Hystad, P., Dzhambov, A. M., ... Fuertes, E. (2017). Exploring pathways linking greenspace to health : Theoretical and methodological guidance. Environmental Research, 158(June), 301-317. http://doi.org/10.1016/j.envres.2017.06.028 
Marquet, O., Alberico, C., \& Hipp, A. J. (2018). Pokémon GO and physical activity among college students. A study using Ecological Momentary Assessment. Computers in Human Behavior, 81, 215-222. http://doi.org/10.1016/j.chb.2017.12.028

Marquet, O., Floyd, M. F., James, P., Glanz, K., Jennings, V., Jankowska, M. M., ... Hipp, J. A. (2019). Associations between worksite walkability, greenness, and physical activity around work. Environment and Behavior, Forthcoming. http://doi.org/10.1177/0013916518797165

Marquet, O., \& Miralles-Guasch, C. (2015). The Walkable city and the importance of the proximity environments for Barcelona's everyday mobility. Cities, 42(PB), 258-266. http://doi.org/10.1016/j.cities.2014.10.012

Matthews, S. A., \& Yang, T.-C. (2013). Spatial Polygamy and Contextual Exposures (SPACEs): Promoting Activity Space Approaches in Research on Place And Health. American Behavioral Scientist, 57(8), 1057-1081. http://doi.org/10.1177/0002764213487345

Natural England. (2010). “Nature Nearby” Accessible Natural Greenspace Guidance. Retrieved from http://www.ukmaburbanforum.co.uk/docunents/other/nature_nearby.pdf

Pathak, V., Tripathi, B. D., \& Mishra, V. kumar. (2008). Evaluation of traffic noise pollution and attitudes of exposed individuals in working place. Atmospheric Environment, 42(16), 3892-3898. http://doi.org/10.1016/j.atmosenv.2007.12.070

Patterson, Z., \& Fitzsimmons, K. (2016). DataMobile. Transportation Research Record: Journal of the Transportation Research Board, 2594, 35-43. http://doi.org/10.3141/2594-07

Pauleit, S., Jones, N., Garcia-Martin, G., Garcia-Valdecantos, J. L., Rivière, L. M., Vidal-Beaudet, L., ... Randrup, T. B. (2002). Tree establishment practice in towns and cities - Results from a European survey. Urban Forestry and Urban Greening, l(2), 83-96. http://doi.org/10.1078/1618-8667-00009

Protogeo. (2016). MOVES. Activity Diary of Your Life. Retrieved March 2, 2017, from https://moves-app.com/

Rissel, C., Curac, N., Greenaway, M., \& Bauman, A. (2012). Physical activity 
associated with public transport use-a review and modelling of potential benefits. International Journal of Environmental Research and Public Health, 9(7), 24542478. http://doi.org/10.3390/ijerph9072454

Robinson, A. I., \& Oreskovic, N. M. (2013). Comparing self-identified and censusdefined neighborhoods among adolescents using GPS and accelerometer. International Journal of Health Geographics, 12, 57. http://doi.org/10.1186/1476072X-12-57

Rojas, C., Páez, A., Barbosa, O., \& Carrasco, J. (2016). Accessibility to urban green spaces in Chilean cities using adaptive thresholds. Journal of Transport Geography, 57, 227-240. http://doi.org/10.1016/j.jtrangeo.2016.10.012

Sallis, J. F., Cain, K. L., Conway, T. L., Gavand, K. A., Millstein, R. A., Geremia, C. M., ... King, A. C. (2015). Is Your Neighborhood Designed to Support Physical Activity? A Brief Streetscape Audit Tool. Preventing Chronic Disease, 12(9), 111. http://doi.org/10.5888/pcd12.150098

Sallis, J. F., Floyd, M. F., Rodriguez, D. A., \& Saelens, B. E. (2012). The Role of Built Environments in Physical Activity, Obesity, and CVD. Circulation, 125(5), 729737. http://doi.org/10.1161/CIRCULATIONAHA.110.969022.The

Sallis, J. F., Frank, L. D., Saelens, B. E., \& Kraft, M. K. (2004). Active transportation and physical activity: Opportunities for collaboration on transportation and public health research. Transportation Research Part A: Policy and Practice, 38(4), 249268. http://doi.org/10.1016/j.tra.2003.11.003

Sarkar, C., Webster, C., \& Gallacher, J. (2018). Residential greenness and prevalence of major depressive disorders: a cross-sectional, observational, associational study of 94879 adult UK Biobank participants. The Lancet Planetary Health, 2(4), e162e173. http://doi.org/10.1016/S2542-5196(18)30051-2

Sarkar, C., Webster, C., Pryor, M., Tang, D., Melbourne, S., Zhang, X., \& Jianzheng, L. (2015). Exploring associations between urban green, street design and walking: Results from the Greater London boroughs. Landscape and Urban Planning, 143, 112-125. http://doi.org/10.1016/j.landurbplan.2015.06.013

Schipperijn, J., Bentsen, P., Troelsen, J., Toftager, M., \& Stigsdotter, U. K. (2013). Associations between physical activity and characteristics of urban green space. 
Urban Forestry and Urban Greening, 12(1), 109-116.

http://doi.org/10.1016/j.ufug.2012.12.002

Shoshany, M. (2012). The rational model of shrubland biomass, pattern and precipitation relationships along semi-arid climatic gradients. Journal of Arid Environments, 78, 179-182. http://doi.org/10.1016/j.jaridenv.2011.10.013

Southworth, M. (2005). Designing the Walkable City. Journal of Urban Planning and Development, 131(December), 246. http://doi.org/10.1061/(ASCE)07339488(2005)131:4(246)

Sugiyama, T., Giles-Corti, B., Summers, J., du Toit, L., Leslie, E., \& Owen, N. (2013). Initiating and maintaining recreational walking: A longitudinal study on the influence of neighborhood green space. Preventive Medicine, 57(3), 178-182. http://doi.org/10.1016/j.ypmed.2013.05.015

Talavera-Garcia, R., \& Soria-Lara, J. A. (2015). Q-PLOS, developing an alternative walking index. A method based on urban design quality. Cities, 45, 7-17. http://doi.org/10.1016/j.cities.2015.03.003

Taylor, M., Wheeler, B., White, M., Economou, T., \& Osborne, N. (2015). Research note: Urban street tree density and antidepressant prescription rates-A crosssectional study in London, UK. Landscape and Urban Planning, 136, 174-179. http://doi.org/10.1016/j.landurbplan.2014.12.005

Toftager, M., Ekholm, O., Schipperijn, J., Stigsdotter, U., Bentsen, P., Grønbæk, M., ... Kamper-Jørgensen, F. (2011). Distance to green space and physical activity: a danish national representative survey. Journal of Physical Activity \& Health, 8(6), 741-749. http://doi.org/10.1123/jpah.8.6.741

Troped, P. J., Wilson, J. S., Matthews, C. E., Cromley, E. K., \& Melly, S. J. (2010). The Built Environment and Location-Based Physical Activity. American Journal of Preventive Medicine, 38(4), 429-438. http://doi.org/10.1016/j.amepre.2009.12.032

Tsai, W., Mchale, M. R., Jennings, V., Marquet, O., Hipp, J. A., Leung, Y., \& Floyd, M. F. (2018). Relationships between Characteristics of Urban Green Land Cover and Mental Health in U . S . Metropolitan Areas. International Journal of Environmental Research and Public Health, 15(2), 340. http://doi.org/10.3390/ijerph15020340 
Vallée, J., Le Roux, G., Chaix, B., Kestens, Y., \& Chauvin, P. (2014). The 'constant size neighbourhood trap' in accessibility and health studies. Urban Studies, 52(2), 1-20. http://doi.org/10.1177/0042098014528393

van Dillen, S. M. E., de Vries, S., Groenewegen, P. P., \& Spreeuwenberg, P. (2012). Greenspace in urban neighbourhoods and residents' health: adding quality to quantity. Journal of Epidemiology \& Community Health, 66(6), e8-e8. http://doi.org/10.1136/jech.2009.104695

van Herzele, A., \& de Vries, S. (2012). Linking green space to health: A comparative study of two urban neighbourhoods in Ghent, Belgium. Population and Environment, 34(2), 171-193. http://doi.org/10.1007/s11111-011-0153-1

Vich, G., Marquet, O., \& Miralles-Guasch, C. (2017). Suburban commuting and activity spaces: using smartphone tracking data to understand the spatial extent of travel behaviour. The Geographical Journal, 183(4), 426-439. http://doi.org/10.1111/geoj.12220

Vich, G., Marquet, O., \& Miralles-Guasch, C. (2018). Green exposure of walking routes and residential areas using smartphone tracking data and GIS in a Mediterranean city. Urban Forestry and Urban Greening, (August), 1-11. http://doi.org/10.1016/j.ufug.2018.08.008

Ward Thompson, C. (2002). Urban open space in the 21st century. Landscape and Urban Planning, 60(2), 59-72. http://doi.org/10.1016/S0169-2046(02)00059-2

WHO. (2010). Global Recomendations on Physical Activity for Health. Geneva. Retrieved from http://www.who.int/dietphysicalactivity/factsheet_recommendations/en/ index.html.

WHO. (2016). Urban green spaces and health: a review of the evidence. Copenhagen.

Witten, K., Blakely, T., Bagheri, N., Badland, H., Ivory, V., Pearce, J., ... Schofield, G. (2012). Neighborhood built environment and transport and leisure physical activity: Findings using objective exposure and outcome measures in New Zealand. Environmental Health Perspectives, 120(7), 971-977. http://doi.org/10.1289/ehp.1104584 